Wayne State University

DigitalCommons@WayneState

Psychology Faculty Research Publications

Psychology

$1-1-2009$

\title{
Perceived Entitlement to Pain-Related Support and Pain Catastrophizing: Associations with Perceived and Observed Support
}

\author{
Annmarie Cano \\ Wayne State University, acano@wayne.edu \\ L Leong \\ Wayne State University \\ J. B. Heller \\ Wayne State University \\ J.R. Lutz \\ Wayne State University
}

\section{Recommended Citation}

Annmarie Cano, Laura Leong, Jaclyn B. Heller, Jillian R. Lutz

Perceived entitlement to pain-related support and pain catastrophizing: Associations with perceived and observed support PAIN, Volume 147, Issues 1-3, 15 December 2009, Pages 249-254

http://dx.doi.org/10.1016/j.pain.2009.09.023

Available at: http://digitalcommons.wayne.edu/psychfrp/12

This Article is brought to you for free and open access by the Psychology at DigitalCommons@WayneState. It has been accepted for inclusion in

Psychology Faculty Research Publications by an authorized administrator of DigitalCommons@WayneState. 
This article is the author's final version after peer-review. A publisher version (Elsevier) of this article previously appeared in Pain, (147(1-3), 2009), available at http://www.sciencedirect.com/science/journal/03043959.

\section{(c) $(9)$}

This article is licensed under a Creative Commons license

http://creativecommons.org/licenses/by-nc-nd/3.0/us/ 


\title{
Perceived Entitlement to Pain-Related Support and Pain Catastrophizing: Associations with Perceived and Observed Support
}

\author{
A. Cano, L. Leong, J.B. Heller, J.R. Lutz \\ Dept. of Psychology, Wayne State University, USA
}

\begin{abstract}
Studies on the determinants of pain-related support are needed to enhance couples-based treatments for pain. The purpose of this study was to determine the extent to which pain catastrophizing and perceived entitlement to pain-related support (i.e., support entitlement) were associated with perceived and observed social support. Participants were 106 chronic pain couples recruited from the community. They completed surveys as well as an observational discussion task. Greater support entitlement in persons with pain was correlated positively with pain catastrophizing, punishing spouse responses, and observed spousal invalidation but negatively correlated with perceived spousal support, solicitous spouse responses, and observed validation. Catastrophizing was correlated with perceptions of general spousal support but not the other support variables. Hierarchical regression analyses demonstrated that among persons with lower levels of support entitlement, catastrophizing was associated with greater solicitous spouse responses. Among those with a greater entitlement to support, catastrophizing was associated with greater punishing spouse responses and observed invalidation by the spouse. These results suggest that support entitlement plays an important role in couples' supportive interactions about pain. Continued research is needed to determine how a desire for pain-related attention and support and catastrophizing translate into behaviors that affect support provision and receipt.
\end{abstract}

Keywords: Pain Catastrophizing; Social Support, Solicitous Spouse Responses, Punishing Spouse Responses, Spousal Support, Chronic Pain, Couples, Spouse 


\title{
Perceived Entitlement to Pain-Related Support and Pain Catastrophizing: Associations with Perceived and Observed Support
}

\author{
A. Cano, L. Leong, J.B. Heller, and J.R. Lutz
}

\section{Introduction}

Despite the recent calls for research on the determinants of social support ${ }^{22}$, few studies have investigated the predictors of spousal support in pain (cf., 4, 5, 24). Identifying the correlates and determinants of spousal support can provide valuable insights as to how social support delivery and receipt can be achieved in couples-based pain interventions. Research has shown that characteristics of the support provider may influence support provision ${ }^{13}$. However, characteristics of the person with pain may be just as important given that one may elicit responses from close others in a variety of ways ${ }^{12,30}$. In this study, we investigate two characteristics of persons with pain-pain catastrophizing and perceived entitlement to support—as correlates of perceived and observed spousal support.

According to the communal coping model, one purpose of pain catastrophizing is to elicit support from close others ${ }^{30,31}$. An implicit and untested assumption of the communal coping model is that some persons who catastrophize desire or feel entitled to more pain-related support or attention. These thoughts and desires may have implications for social support seeking and provision. Evidence from the pain field has demonstrated that pain catastrophizing is positively associated with refraining from talking about pain concerns with one's partner ${ }^{27}$. In fact, some people with pain do not directly disclose their pain experience to others because they expect negative social reactions ${ }^{25}$. This research also finds that some persons with pain rely on indirect methods of communicating pain such as body posture and facial expressions as opposed to verbally disclosing their distress more directly. People who catastrophize or who feel entitled to support may be especially prone to indirect support seeking attempts because of negative social expectations. Unfortunately, indirect support seeking behaviors tend to be aversive for potential support providers 3 , 33, who react with unsupportive or rejecting behaviors. It is also possible that perceived entitlement indirectly conveys that the person is more interested in receiving than giving support. Spouses may perceive the inequity in support provision and receipt, which could contribute to spousal distress and unsupportive behaviors ${ }^{2,21}$.

In this cross-sectional study of chronic pain couples, we hypothesized that perceived entitlement to support would be positively related to pain catastrophizing, and that both of these variables would be inversely related to spousal support. We also investigated the possible mediation of 
catastrophizing and support entitlement in relating to support. Last, based on social support provision models, we expected that perceived entitlement would moderate the associations between catastrophizing and support. Specifically, stronger feelings of entitlement combined with higher levels of catastrophizing may be especially frustrating for close others, who engage in unsupportive and invalidating behaviors. To expand the investigation of pain-related support to observable behaviors, we also assessed spousal support during a discussion task about the pain problem. 


\section{Method}

\subsection{Participants}

The initial sample consisted of 108 couples residing in the community. Women comprised $54.6 \%$ of the persons with chronic pain. Approximately 49\% $(\mathrm{n}=53)$ of persons with pain self-reported as African American, another 49\% ( $\mathrm{n}=53)$ self-reported as Caucasian, and approximately $2 \%(n=2)$ reported as another race. This distribution was similar for spouse participants (Caucasians: 51\%, $\mathrm{n}=55$; African Americans: 47\%, $\mathrm{n}=51$; other groups: 2\%, $\mathrm{n}$ $=2$ ). The mean age of persons with pain was 52.03 years $(\mathrm{SD}=13.40)$, and the mean age of spouses was 51.85 years $(\mathrm{SD}=13.49)$. On average, couples had completed some college (persons with pain: $\mathrm{M}=14.31$, $\mathrm{SD}=3.03$; spouses: $\mathrm{M}=13.95$ years, $\mathrm{SD}=2.88$ ). Mean marriage duration was 21.73 years $(\mathrm{SD}=15.71)$. Mean household income was $\$ 46,447$ (SD $=\$ 24,112)$ and was obtained from block-level group income information in the U.S. Census. The back or neck was the most frequently reported as the site of worst pain $(\mathrm{n}=70 ; 65 \%)$. The most common chronic pain problems reported were back problems (e.g., degenerative disc disease, herniated disc, pain from spinal fusion; $\mathrm{n}=59,54.6 \%)$ and Osteoarthritis $(\mathrm{n}=$ $38,35.2 \%)$. Persons with pain reported an average pain duration of 11.71 years $(\mathrm{SD}=10.50)$ and a mean pain intensity score of $5.37(\mathrm{SD}=2.05)$ on a 4-item measure (current, average, worst, and least pain; $\alpha=.89)$ using a numerical rating scale $(0-10$ scale $)$.

\subsection{Measures}

Partners with chronic pain completed the self-report measures. Their spouses' supportive behaviors were assessed in the observational task described below.

\subsubsection{Perceived Entitlement to Pain-Related Support}

The Survey of Pain Attitudes (SOPA ${ }^{17}$ ) assesses beliefs and attitudes regarding pain. The original SOPA has 7 subscales, one of which is the 6-item Solicitude subscale, which was designed to assess attitudes concerning the responsibility of others to provide painrelated support. Because the term "solicitude" is not often used in the pain literature and is more accurately defined as anxious, special, or particular care or attention ${ }^{1}$ (OED), we use the term support entitlement. Items include "When I hurt, I want my family to treat me better," "When I am hurting, I deserve to be treated with care and concern," "It is the responsibility of my family to help me when I feel pain," "My family needs to learn how to take better care of me when I am in pain," "My family does not understand how much pain I am in," and "I need more tender loving care than I am now getting when I am in pain." 
Higher scores indicated a greater perceived entitlement to pain-related support. Participants responded on a 5-point Likert-type scale $(0=$ untrue for me and $4=$ very true for me). Inter-item reliability in the current study was adequate $(\alpha=.74)$.

\subsubsection{Pain Catastrophizing}

Pain Catastrophizing was assessed with the Pain Catastrophizing Scale (PCS ${ }^{29}$ ). The PCS assesses three dimensions of catastrophizing about pain: magnification, rumination, and helplessness ${ }^{29}$, 32. These subscales were significantly correlated with one another in the current sample ( $r$ s ranged from .54 to $.68, \mathrm{p}<.0001$ ). The total catastrophizing score was used to ensure the full range of catastrophizing cognitions were assessed. Internal consistency was excellent in the current study $(\alpha=.92)$.

\subsubsection{Support Measures}

Spouse responses to pain were assessed with the Multidimensional Pain Inventory $\left(\mathrm{MPI}^{20}\right)$. Perceptions of spouse punishing (4 items), solicitous (6 items), and distracting (4 items) responses to pain were measured. Subscale sums were used in the analyses. Interitem reliability was adequate to excellent for the subscales (punishing $\alpha=.84$, solicitous $\alpha=$ .83 , distracting $\alpha=.69$ ). One participant did not complete the punishing items. The mean for the sample was entered for this participant to ensure a consistent sample size across analyses. Because of the low inter-item reliability for the distracting subscale and its high correlation with solicitous responses $(r=.70, \mathrm{p}<.0001)$, we do not include distracting responses in further analyses.

Perceived spousal support was measured with a romantic partner-specific support scale (12 items ${ }^{8}$ ). Higher scores indicate greater perceived support from the spouse. Note that this scale measures support more generally, rather than examining pain-specific support. In the current study, inter-item reliability was excellent (spousal support $\alpha=.87$ ). The mean for the sample was entered for the one participant who did not complete this scale to ensure a consistent sample size across analyses.

Observed support behaviors were assessed during two 10-minute interaction tasks about the pain problem. The Validation and Invalidation Behavior Coding System ${ }^{10}$ was used to assess supportive and unsupportive responses during an interaction about pain. Each partner's validating and invalidating responses were coded but only spouses' responses are used in the current study since the focus of this study is on spousal support. Validation includes empathic and supportive responses to the partner's emotional expressions (e.g., questions aimed at understanding the thoughts and feelings of the partner). Invalidation 
consists of negative responses to a partner's emotional expressions (e.g., inattentiveness to a partner's emotion, changing the subject, telling the spouse what they should be thinking or feeling, or denigrating the spouse). Raters coded global validation and invalidation on a Likert-type scale ranging from 1 (validation: no validation above basic attention; invalidation: no invalidation) to 7 (only validation/invalidation). An advantage of such global methods of coding interaction is that these systems provide simultaneous coding across dimensions of interaction (e.g., quantity and quality, non-verbal and verbal) ${ }^{23}$.

Each interaction was coded by 4-6 raters, all of whom were trained by the first author. Raters participated in 5 weeks of training, which consisted of education in couple interaction and observational research issues, reading the training manual, and in-session and practice coding of videotapes from a previous study. Once coders were reliable with the first author and other coders, they were able to code interactions for this study. Coders were not blind to the identity of the patient because the topic of discussion was the impact of pain but coders were blind to survey responses. Coders were allowed to watch the tapes as many times as was necessary to make confident coding decisions.

Inter-rater agreement was assessed with the $r_{w g(j)}$ statistic, which is calculated from observed and expected variances across coders and items 16. Like other measures of agreement for continuous variables, $\mathrm{r}_{\mathrm{wg}(\mathrm{j})}$ accounts for random measurement-error variance. This measure also accounts for the amount of systematic variance that reflects rater response bias and is used when there are at least 2 parallel items for each measure (i.e., in this study, $j=2$ ratings because there were two interactions, as described in the Procedure). Other measures of agreement or consistency on continuous variables such as intra-class correlation, \% agreement, and correlation-based estimates between raters are unsuitable for data like ours because videos were watched by different subsets of trained coders. Furthermore, these other measures do not allow for restriction of range, which can happen when a coder rates validation of the spouse similarly across the two discussions or a group of raters agrees on spouse invalidation ratings across the two interactions ${ }^{15,16}$. Similarly, other measures assess absolute agreement or consistency in proportions, or do not allow parallel measures across raters, as was the case in this study (i.e., 2 interactions). $R_{\mathrm{wg}(2)}$ values approaching 1.0 indicate excellent agreement. Agreement was poor for 4 codes across 4 spouses $\left(r_{\mathrm{wg}(2)}<.60\right)$. Therefore, mean scores for these individuals were deleted and not used in further analyses. $R_{\mathrm{wg}(2)}$ was excellent for validation in spouses (mean $r_{\mathrm{wg}(2)}=.89$ ). 
Agreement was also excellent for invalidation in spouses (mean $r_{\mathrm{wg}(2)}=.90$ ). Mean scores were relatively low (validation $\mathrm{M}=2.41, \mathrm{SD}=.67$; invalidation $\mathrm{M}=1.88, \mathrm{SD}=.84$ ).

\subsection{Procedure}

This study was approved by the university's institutional review board. Newspaper and online advertisements at the university were used to recruit participants for a longitudinal research study of couples with chronic pain. The first wave of data was used for this manuscript. Telephone screenings were used to determine the eligibility of callers. Callers were told that the research study was being conducted to determine the positive and negative experiences of couples dealing with pain and that the study did not entail treatment. Eligible participants were at least 21 years old and currently married or living together for at least 2 years. Couples were ineligible if either partner reported psychotic symptoms, somatoform/somatization symptoms, an autoimmune or terminal illness, or if over the age of 60, failed a telephone-adapted mental status examination. At least one spouse reported a chronic benign pain condition of at least 6 months duration. If both partners reported chronic benign pain, the spouse with the more severe or disabling pain by both partners' reports was labeled as the partner with pain.

Eligible couples completed consent forms and surveys and attended a 3-hour lab session during which they engaged in a mood interview (not part of the current study) and two 10-minute interaction tasks that were recorded on video. Prior to the interaction, trained interviewers spent 5 minutes with each spouse individually to elicit their thoughts and feelings about how pain had affected their lives. Participants were then escorted to a video observation room where the interviewers instructed the couple to discuss these thoughts and feelings in two separate interactions, one led by the partner with pain and one led by the spouse. Couples were instructed to behave as naturally as possible and to be fully engaged in both discussions. Upon completion of this session, all couples were debriefed and compensated $\$ 100$ for their time and effort. A referral list of various types of psychological services (e.g., therapists, support groups) was also provided to all participants in case they decided to seek counseling in the future.

\subsection{Data Analytic Strategy}

An examination of the Mahalanobis distances showed that there were no multivariate outliers. One participant reported a pain duration of less than 6 months and there was one 
univariate outlier on pain catastrophizing. These two participants were omitted so that $\mathrm{N}=$ 106 for the analyses on self-report data. The observed support analyses rely on a smaller sample size $(\mathrm{N}=94)$ because of technical problems (e.g., inaudible videos due to equipment malfunction) or unusable data due to low inter-rater reliability for particular spouses as described above.

Correlation analyses were first conducted to determine the bivariate relationships between support entitlement, pain catastrophizing, and the support variables (i.e., perceived spousal support, perceived solicitous and punishing spouse responses, and observed validation and invalidation expressed by the spouse during interaction).

A series of 5 hierarchical regressions were then conducted to examine the relative contributions of support entitlement and pain catastrophizing as well as the interaction between these two variables in relating to the support variables. Independent variables were centered prior to entry in the regression analyses. Possible mediation was examined if pain catastrophizing and support entitlement were significantly related to the same type of support. Significant interactions were further investigated by conducting additional regression analyses to produce simple slopes for pain catastrophizing relating to perceived spousal support at high [+1 SD] and low [-1 SD] levels of support entitlement ${ }^{14}$.

\section{Results}

\subsection{Correlations}

Greater support entitlement was positively correlated with pain catastrophizing $(\mathrm{r}=.23, \mathrm{p}$ $<$.05). Table 1 displays the correlations between catastrophizing, support entitlement, and the support variables. Greater support entitlement was related to perceptions of lower spousal support and solicitous spouse responses as well as less spousal validation during interaction. In contrast, greater support entitlement was related to greater punishing spouse responses and greater spousal invalidation during interaction. Higher scores on catastrophizing were related to lower spousal support. The support variables were also significantly correlated with one another (see Table 1) with the exceptions of observed invalidation with solicitous spouse responses, and observed validation with perceived spousal support, although the latter approached significance $(\mathrm{p}<.06)$. 


\begin{tabular}{|c|c|c|c|c|c|c|}
\hline & $\begin{array}{l}\text { Pain } \\
\text { Catastrophizing }\end{array}$ & $\begin{array}{c}\text { Support } \\
\text { Entitlement }\end{array}$ & $\begin{array}{l}\text { Solicitous } \\
\text { Responses }\end{array}$ & $\begin{array}{l}\text { Punishing } \\
\text { Responses }\end{array}$ & $\begin{array}{l}\text { Spousal } \\
\text { Support }\end{array}$ & $\begin{array}{c}\text { Spousal } \\
\text { Invalidation }\end{array}$ \\
\hline $\begin{array}{l}\text { Solicitous } \\
\text { Spouse Responses }\end{array}$ & .10 & $-.27^{* *}$ & -- & & & \\
\hline $\begin{array}{l}\text { Punishing } \\
\text { Spouse Responses }\end{array}$ & .15 & $.37^{* * *}$ & $-.33^{* *}$ & -- & & \\
\hline Spousal Support & $-.24^{*}$ & $-.38 * * *$ & $.36^{* * *}$ & $-.42 * * *$ & -- & \\
\hline $\begin{array}{l}\text { Spousal } \\
\text { Invalidation }\end{array}$ & .14 & $.28^{* *}$ & -.05 & $.26^{* *}$ & $-.28^{* *}$ & -- \\
\hline $\begin{array}{l}\text { Spousal } \\
\text { Validation }\end{array}$ & .14 & $-.25 *$ & $.25^{*}$ & -.16 & .20 & $-.37 * * *$ \\
\hline
\end{tabular}

$\mathrm{N}=106$ couples except for Spousal Invalidation and Validation, where $\mathrm{N}=94$ couples.

${ }^{*} \mathrm{p}<.05 .{ }^{* *} \mathrm{p}<.01 .{ }^{* * *} \mathrm{p}<.001$.

Table 1. Correlations Among Pain Catastrophizing, Support Entitlement, and Support Variables

\subsection{Hierarchical Regressions: Mediation and Moderation}

Hierarchical regression analyses demonstrated that support entitlement mediated but did not moderate the association between pain catastrophizing and perceived spousal support (see Table 2). The mediational effect was significant $(z=-1.99, p<.05)$, demonstrating that approximately 33\% of the effect of pain catastrophizing on perceived spousal support was accounted for by feelings of entitlement to pain-related support and attention. However, support entitlement did not significantly interact with pain catastrophizing in relating to perceived spousal support. 
\begin{tabular}{lr} 
Step $1 \quad$ Step 2 \\
\hline
\end{tabular}

\begin{tabular}{|c|c|c|c|c|c|c|c|c|}
\hline \multirow[b]{2}{*}{ Dependent Variable } & \multicolumn{2}{|c|}{$\begin{array}{c}\text { Support } \\
\text { Entitlement }\end{array}$} & \multicolumn{2}{|c|}{$\begin{array}{l}\text { Pain } \\
\text { atastrophizing }\end{array}$} & \multicolumn{4}{|c|}{$\begin{array}{l}\text { Support Entitlement } \\
\text { X } \\
\text { Pain Catastrophizing }\end{array}$} \\
\hline & Beta & $\mathrm{t}$ & Beta & $\mathrm{t}$ & $\mathrm{R}^{2}$ & Beta & $\mathrm{t}$ & $\Delta \mathrm{R}^{2}$ \\
\hline Solicitous Spouse Responses & -.30 & $-3.14^{* *}$ & .16 & 1.71 & $.10^{* *}$ & -.23 & $-2.51^{*}$ & $.05^{*}$ \\
\hline Punishing Spouse Responses & .35 & $3.72^{* *}$ & .07 & .71 & $.14^{* *}$ & .19 & $2.08^{*}$ & $.04^{*}$ \\
\hline Perceived Spousal Support & -.34 & $-3.70 * *$ & -.16 & -1.72 & $.17^{* *}$ & .00 & .05 & .00 \\
\hline Spousal Invalidation & .26 & $2.59^{*}$ & .09 & .93 & $.09^{*}$ & .14 & 1.36 & .02 \\
\hline Spousal Validation & -.30 & $-2.91^{* *}$ & .20 & $1.99^{*}$ & $.10^{*}$ & .00 & .04 & .00 \\
\hline
\end{tabular}

${ }^{*} \mathrm{p}<.05 .{ }^{* *} \mathrm{p}<.01 . \mathrm{N}=106$ couples except for Spousal Invalidation and Validation, where $\mathrm{N}=94$ couples.

Table 2. Hierarchical Regressions Predicting Spousal Support from Support Entitlement and Pain Catastrophizing. 
Because pain catastrophizing was not significantly related to other forms of support, mediation could not be examined for the other support variables. As shown in Table 2, moderator analyses demonstrated a significant interaction for solicitous and punishing spouse responses, indicating that the association between catastrophizing and these forms of support differs depending on support entitlement.

Specifically, among persons with low support entitlement (- 1SD on the solicitude subscale), catastrophizing was associated with greater solicitous spouse responses $(b=.31$, $\mathrm{SE}=.11$, Beta $=.37, \mathrm{t}=2.97, \mathrm{p}<.01$; See Figure 1). Catastrophizing was not significantly related to solicitous responses at high levels of support entitlement $(b=-.04, \mathrm{SE}=.11$, Beta $=-.04, \mathrm{t}=-.35, \mathrm{p}>.72)$.

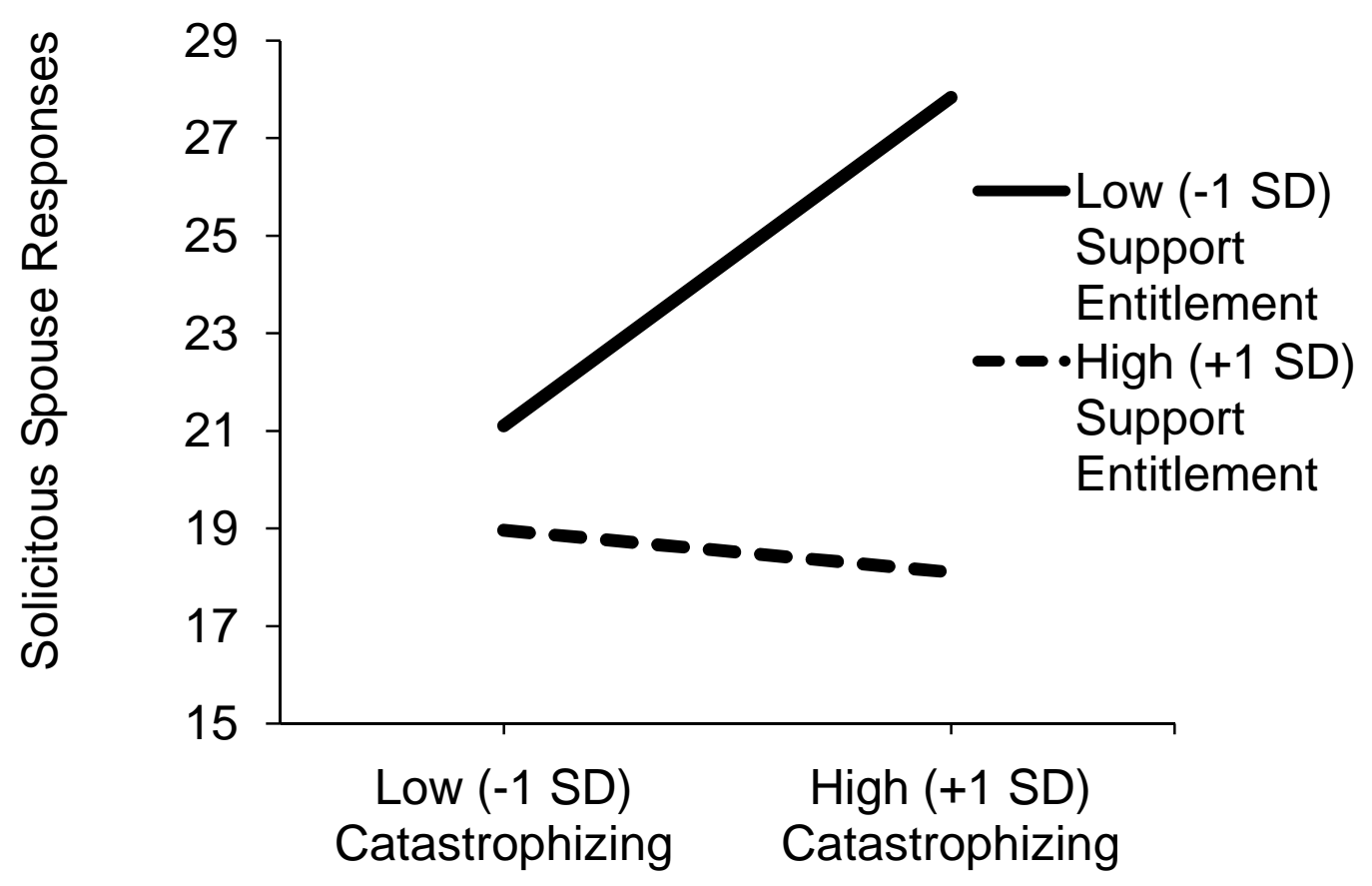

Figure 1. The interaction between support entitlement and pain catastrophizing in relating to solicitous spouse responses. Analysis of the simple slopes indicated that pain catastrophizing was positively related to solicitous spouse responses to pain among participants with lower entitlement to support (-1 SD) whereas catastrophizing and solicitous spouse responses were not significantly related when entitlement to support was high (+1 SD). 
In contrast, among those with high levels of support entitlement (+ $1 \mathrm{SD}$ on the solicitude subscale), catastrophizing was associated with greater punishing spouse responses $(b=.14$, $\mathrm{SE}=.07$, Beta $=.24, \mathrm{t}=1.92, \mathrm{p}<.06$; See Figure 2). Catastrophizing was not significantly related to punishing responses at low levels of support entitlement $(b=-.06, \mathrm{SE}=.07$, Beta $=-.10, \mathrm{t}=-.83, \mathrm{p}>.41)$.

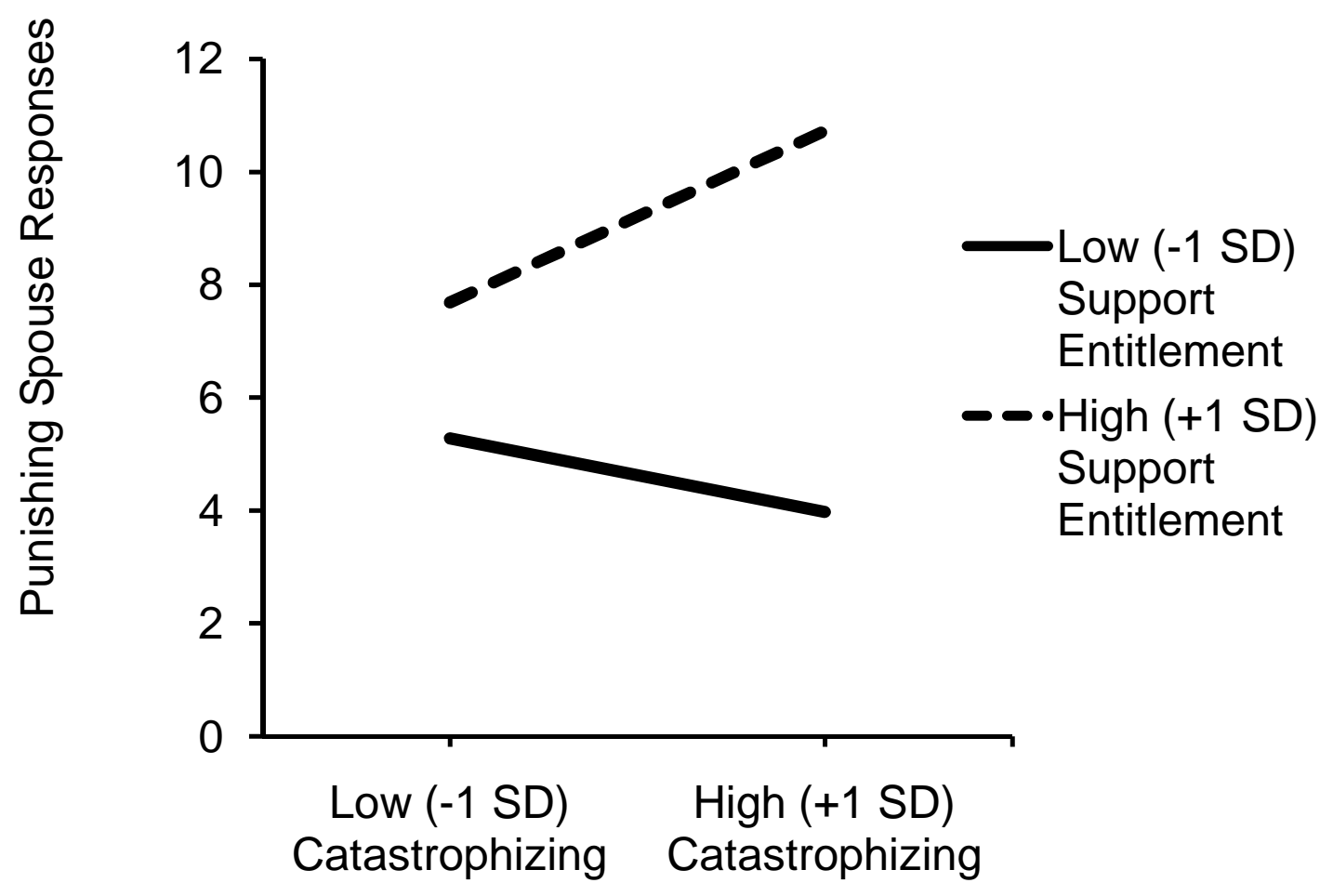

Figure 2. The interaction between support entitlement and pain catastrophizing in relating to punishing spouse responses. Analysis of the simple slopes indicated that pain catastrophizing was positively related to punishing spouse responses to pain among participants with greater support entitlement (+1 SD) whereas catastrophizing and punishing spouse responses were not significantly related when support entitlement was low (-1 SD). 
Moderation was not demonstrated for observed validation and invalidation. Interestingly, regressing spousal validation onto support entitlement and pain catastrophizing resulted in a slightly stronger association of each independent variable, (support entitlement: Beta = $.30, \mathrm{p}<.01$ vs. $\mathrm{r}=-.25, \mathrm{p}<.05$ and catastrophizing: Beta $=.20, \mathrm{p}=.05$ vs. $\mathrm{r}=.14, \mathrm{p}<.20)$. This pattern of findings suggests cooperative suppression ${ }^{34}$, in which each independent variable removes variance that is irrelevant to the association between the other independent variable and validation.

\section{Discussion}

The purpose of this study was to investigate pain catastrophizing and perceived entitlement to pain-related support as correlates of social support. Extending the communal coping model of pain ${ }^{30,31}$, we hypothesized that persons who felt entitled to received painrelated support would also engage in greater pain catastrophizing. As expected, entitlement to support was positively related to catastrophizing. While we cannot make conclusions regarding the temporal or causal relationships between these variables, this result provides preliminary evidence regarding the relevance of desires for or expectations of support in research on catastrophizing.

We also hypothesized that both pain catastrophizing and support entitlement would relate to perceived and actual support. Each of these cognitive styles may result in indirect support seeking behaviors ${ }^{25,27}$ that are often perceived in a negative manner by significant others 3, 33 who then respond with unsupportive behaviors. Support entitlement was consistently related to the social support variables while pain catastrophizing was not. Furthermore, perceived entitlement accounted for the relationship between catastrophizing and perceptions of general spousal support. Helplessness about pain may activate a need for greater soothing or support from close others, which in turn, leads to potentially maladaptive support-seeking behaviors. It is possible that relying on a strategy of indirect support-seeking results in a loss of support over time ${ }^{5}$. Alternatively, support providers may perceive an inequitable exchange of support when their partners feel entitled to support ${ }^{2}$, 21. Longitudinal and experimental data are needed to test these hypotheses. Furthermore, additional work is needed to identify the specific support behaviors that are affected by 
support entitlement since statistical mediation was found only for perceived spousal support.

The hypothesis that support entitlement would moderate the relationship between catastrophizing and support was partially supported. Greater catastrophizing was associated with greater pain-related support (i.e., solicitous spouse responses) among participants who felt less entitled about receiving pain-related support. It may be easier or more satisfying to provide pain-related support to spouses who do not demand or feel entitled to support. In these cases, support provision may feel more voluntary or altruistic. In addition, persons with less support entitlement may more directly communicate their needs to their partners. Direct support-seeking, such as asking for help, allows partners to feel more confident about their ability to help and often results in comforting or supportive behavior ${ }^{3}$. These findings also have implications for the communal coping model's hypotheses regarding the role of catastrophizing in eliciting support. It is possible that this is true among persons who do not have a sense of support entitlement.

Among participants with a greater sense of entitlement, greater catastrophizing was related to more negative or punishing spouse responses. Greater feelings of entitlement might be enacted with negative emotional displays or other behaviors that make support provision feel like chore or a response to a demand. It may also be more difficult for partners to know how to be supportive to someone with feelings of support entitlement. Perceptions of fairness may also come into play. For instance, individuals with feelings of entitlement may express the need for additional support, directly or indirectly, while discontinuing disliked but continuing to engage in liked activities. This pattern of behavior would be perceived as unfair $^{19}$ and may result in perceptions of inequitable support provision between partners. In turn, spouses may react with negative or invalidating responses. Repeated failures to obtain the support one expects or desires may also result in negative emotional expressions directed to the partner, which in turn, may affect painrelated emotional regulation processes at the individual and couple levels ${ }^{6,18}$. Observational and daily diary studies in which direct and indirect requests for support, spouse responses, and pain behaviors are assessed may be especially well-suited to the further exploration of these possibilities.

We also had the unique opportunity to analyze spouses' observed supportive and unsupportive behaviors in the context of a discussion about pain. Greater perceived entitlement was associated with greater spousal invalidation and lower spousal validation 
in the observational interaction task. Pain catastrophizing was not significantly correlated in a bivariate manner with observed support behaviors. However, when entered with support entitlement, pain catastrophizing became a significant correlate of validation. The regression coefficient for support entitlement was also slightly larger than its bivariate counterpart. These findings may seem at odds with the mediation effects found for general spousal support and the interaction effects reported for self-reported spouse responses. In the former, support entitlement accounted for catastrophizing's association with perceived spousal support and in the latter, particular combinations of entitlement and catastrophizing related to spouse responses to pain. However, each independent variable appears to relate to observed validation in a way that is fairly distinct from the other. One reason for the differences might be due to our reliance on multiple types of social support (e.g., general vs. pain-specific) and different methods of assessment (e.g., self-report vs. observation). For instance, pain catastrophizing may result in particular verbalizations or behaviors that communicate helplessness during interaction. Validation may be a natural response to such helplessness. In contrast, people expecting more support may indirectly convey their dissatisfaction with the partner's support behaviors but not offer ideas as to what would be more beneficial. Indeed, the items of the solicitude scale do not describe specific support behaviors but only general desires regarding support provision. In any event, the pattern of results across self-report and observational data suggests that a robust association exists between perceived entitlement and support but that this association depends on the form of support.

As described earlier, the cross-sectional nature of the study prevents us from making conclusions regarding the causal nature of the support entitlement in contributing to pain catastrophizing and supportive behaviors. Another limitation of this study is that the sample consisted of self-selected heterosexual couples that agreed to participate in a longitudinal study. It remains to be seen if the results can be replicated in other samples of dyads. Finally, the concept of support entitlement may benefit from additional refinement. Research is needed to determine the extent to which this construct overlaps with and is related to other social support and communal coping variables, including desire for different types of support as well as satisfaction with pain-related support. For instance, work by Cutrona \& Russell ${ }^{9}$ suggests that receiving support that matches one's desired type of support is most conducive to effective coping. It is possible that people who score high on solicitude are not receiving optimally matching support. Research is also necessary to 
directly investigate the barriers to the provision of the quantity or quality of support desired by persons with pain. For instance, spouses' own catastrophizing about their partner's pain ${ }^{7}$ may increase the difficulty with which spouses can attend to the support needs of their partners.

A recent study showed that pain catastrophizing, but not pain behaviors, was associated with spouses' accuracy of pain estimations during a painful task ${ }^{11}$. Thus, continued work is needed to determine the behavioral manifestations of catastrophizing thoughts ${ }^{31}$. Similarly, work will be needed on the manner in which feelings of support entitlement are communicated to close others. Although some work suggests that persons with pain may refrain from talking about the pain because of anticipated social consequences ${ }^{25}$, other research shows that most spouses do not hold back from talking about pain with their partners ${ }^{27}$. However, greater holding back or a lower self-efficacy in pain communication is related to poorer adjustment ${ }^{27}$. It may be interesting to investigate the specific aspects of pain that are more difficult to talk about (e.g., factual information vs. emotions and requests for support).

In sum, the results of this study suggest that feelings of entitlement to pain-related support and attention is a significant correlate of perceived and actual support in chronic pain couples. Furthermore, the findings indicate that perceived entitlement may work with pain catastrophizing in communicating one's support needs to close others. Clinicians working with couples may wish to inquire about preferences for support, the types of support received, and the manner in which persons with pain express their need for support to close others to understand the interaction dynamics that might be affecting patient ability to cope with pain. The current findings suggest that such detailed information would also be beneficial in further developing couples' treatments aimed at improving social support delivery. Specifically, prior to moving forward with training on particular coping skills, it may be helpful to directly address both partners' perceptions and expectations about the kind of support that should be provided. Furthermore, it may be helpful to understand the factors that underlie or motivate desires for greater pain-related support and attention (e.g., history of invalidation, lack of empathy or understanding about pain ${ }^{12}$ ) so that these experiences can be openly and sensitively discussed in the context of treatment. 


\section{Acknowledgements}

This research was supported by grant K01 MH 066975 awarded to the first author. The authors have no conflicts of interest to report. 


\section{References}

1. "Solicitude, n.". The Oxford English Dictionary 1989 [cited March 23, 2009]; 2nd Edition:[Availablefrom:http://dictionary.oed.com.proxy.lib.wayne.edu/cgi/entry/50230334?sing] $\mathrm{e}=1 \& q u e r y$ type=word\&queryword $=$ solicitude\&first=1\&max to_show $=10$.

2. Antonucci TC, Jackson JS. The role of reciprocity in social support, in Social support: An interactional view, BR Sarason, IG Sarason, and GR Pierce, Editors. 1990, John Wiley: New York. p. 173-198.

3. Barbee AP, Rowatt TL, Cunningham MR. When a friend is in need: Feelings about seeking, giving, and receiving social support, in Handbook of communication and emotion: Research, theory, applications, and contexts, PA Anderson and LK Guerrero, Editors. 1998, Academic Press: San Diego, CA. p. 281-301.

4. Buenaver LF, Edwards, R.R., Haythornthwaite, J.A.: Pain-related catastrophizing and perceived social responses: Inter-relationships in the context of chronic pain. Pain 127: 234, 2007.

5. Cano A: Pain catastrophizing and social support in married individuals with chronic pain: the moderating role of pain duration. Pain 110: 656-664, 2004.

6. Cano A, Barterian JA, Heller JB: Empathic and nonempathic interaction in chronic pain couples. Clinical Journal of Pain 678-684, 2008.

7. Cano A, Leonard, M.T., Franz, A.: The Significant Other Version of the Pain Catastrophizing Scale (PCS-S): Preliminary validation. Pain 119: 26-37, 2005.

8. Cutrona C: Ratings of social support by adolescents and adult informants: Degree of correspondence and predication of depressive symptoms. Journal of Personality \& Social Psychology 57: 723-730, 1989.

9. Cutrona CE, Russell D. Type of social support and specific stress: Toward a theory of optimal matching, in Social support: An interactional view, IG Sarason, BR Sarason, and GR Pierce, Editors. 1990, Wiley: New York. p. 319-366.

10. Fruzzetti AE: Validation and Invalidation Coding System. Unpublished manuscript 2001.

11. Gauthier N, Thibault P, Sullivan MJL: Individual and relational correlates of pain-related empathic accuracy in spouses of chronic pain patients. Clinical Journal of Pain 24: 669-577, 2008.

12. Goubert L, Craig K, Vervoort T, Morley S, Sullivan MJL, Williams ACdC, Cano A, Crombez G: Facing others in pain: the effects of empathy. Pain 118: 285-288, 2005.

13. Hinnen C, Hagedoorn M, Sanderman R, Ranchor AV: The role of distress, neuroticism and time since diagnosis in explaining support behaviors in partners of women with breast cancer: 
results of a longitudinal analysis. Psycho-Oncology 16: 913-919, 2007.

14. Holmbeck G: Post-hoc probing of significant moderational and mediational effects in studies of pediatric populations. Journal of Pediatric Psychology 27: 87-96, 2002.

15. James LR, Demaree, R.G., \& Wolf, G.: rwg: An Assessment of Within-Group Interrater Agreement. Journal of Applied Psychology 78: 306-309, 1993.

16. James LR, Demaree, R.G., \& Wolf, G.: Estimating Within-Group Interrater Reliability With and Without Response Bias. Journal of Applied Psychology. Journal of Applied Psychology 69: 85-98, 1984.

17. Jensen MP, Turner JA, Romano JM, Lawler BK: Relationship of pain-specific beliefs to chronic pain adjustment. Pain 57: 301-309, 1994.

18. Johansen $\mathrm{AB}$, Cano, A.: A preliminary investigation of affective interaction in chronic pain couples. Pain 132: S86-S95, 2007.

19. Kappesser J, Williams ACdC: Pain judgements of patients' relatives: Examining the use of contract theory as theoretical framework. Journal of Behavioral Medicine 31: 309-317, 2008.

20. Kerns RD, Turk DC, Rudy TE: The West Haven-Yale Multidimensional Pain Inventory (WHYMPI). Pain 23: 345-356, 1985.

21. Kleiboer AM, Kuijer R, Hox JJ, Schreurs KMG, Bensing JM: Receiving and providing support in couples dealing with multiple sclerosis: A diary study using an equity perspective. Personal Relationships 13: 485-501, 2006.

22. Lakey B, Cohen S. Social support theory and measurement, in Social support measurement and intervention: A guide for health and social scientists, S Cohen, LG Underwood, and BH Gottlieb, Editors. 2005, Oxford University Press: New York. p. 29-52.

23. Margolin G, Oliver PH, Gordis EB, O'Hearn HG, Medina AM, Ghosh CM, Morland L: The Nuts and Bolts of Behavioral Observation of Marital and Family Interaction. Clinical Child and Family Psychology Review 1: 195-213, 1998.

24. Martire LM, Keefe FJ, Schulz R, Ready R, Beach SR, Rudy TE, Starz TW: Older spouses' perceptions of partners' chronic arthritis pain: Implications for spousal responses, support provision, and caregiving experiences. Psychology and Aging 21: 222-230, 2006.

25. Morley S, Doyle K, Beese A. Talking to others about pain: Suffering in silence, in Proceedings of the ninth world congress on pain: Progress in pain research and management, $\mathrm{M}$ Devor, $\mathrm{M}$ Rowbotham, and Z Wiesenfeld-Hallin, Editors. 2000, IASP Press: Seattle. p. 1123-1129.

26. Overall NC, Fletcher JO, Simpson JA: Regulation processes in intimate relationships: The role of ideal standards. Journal of Personality and Social Psychology 91: 662-685, 2006.

27. Porter LS, Keefe FJ, Wellington C, Williams ACdC: Pain communication in the context of osteoarthritis: patient and partner self-efficacy for pain communication and holding back from discussion of pain and arthritis-related concerns. Clinical Journal of Pain 24: 662-668, 2008. 
28. Simpson JA, Fletcher GJO, Campbell L. The structure and function of ideal standards in close relationships, in Blackwell Handbook of Social Psychology: Interpersonal Processes GJO Fletcher and M Clark, Editors. 2001, Blackwell: Oxford. p. 86-106.

29. Sullivan MJL, Bishop S, Pivik J: The pain catastrophizing scale: Development and Validation. Psychological Assessment 7: 432-524, 1995.

30. Sullivan MJL, Thorn B, Haythornthwaite JA, Keefe F, Martin M, Bradley LA, Lefebvre JC: Theoretical perspectives on the relation between catastrophizing and pain. Clinical Journal of Pain 17: 52-64, 2001.

31. Thorn BE, Ward LC, Sullivan MJL, Boothby JL: Communal coping model of catastrophizing: conceptual model building. Pain 106: 1-2, 2003.

32. Van Damme S, Crombez G, Bijttebier P, Goubert L, Van Houdenhove B: A confirmatory factor analysis of the Pain Catastrophizing Scale: invariant factor structure across clinical and nonclinical populations. Pain 96: 319-324, 2002.

33. Williams SL, Mickelson KD: A paradox of support seeking and rejection among the stigmatized. Personal Relationships 15: 493-509, 2008.

34. Wuensch K, Redundancy and Suppression in Trivariate Regression Analysis. 2008: http://core.ecu.edu/psyc/wuenschk/StatsLessons.htm. 